\title{
EXPLORING THE SUSTAINABILITY OF DAIRY FARMING IN KERALA: A STOCHASTIC COST FRONTIER APPROACH
}

\author{
Elsa Elizabeth Jacob ${ }^{1}$, A.S.Ambily ${ }^{2}$ \\ \{elsajacob082@gmail.com ${ }^{1}$, ambilysanjayan@gmail.com² $\}$
}

\begin{abstract}
Research Scholar, Department of Commerce and Management, Amrita School of Arts and Sciences, Kochi, India

1 ,

Assistant Professor, Department of Commerce and Management, Amrita School of Arts and Sciences, Kochi, India
\end{abstract}

\begin{abstract}
India is one of the largest milk-producing country, but due to the steady success of milk production.Due to the fast mode of urbanization, people getting into this sector are reducing. The cost of production is also increasing in India. The study is undertaken in Kerala State in India, where milk production is not having a linear growth for the past few years.Allocative efficiency estimation is used to analyze the sustainability of dairy farming in Kerala using stochastic cost frontier method.A total of 150 samples were chosen to estimate efficiency. The mean allocative efficiency was high in Thiruvanthapuram district with 66.56 per cent. Malappuram district has 63.48 per cent, and Ernakulam district has 61.22 per cent. There is still room to improve efficiency further. Only if the farmers increase their efficiency, dairy farming can be sustainable for the future generation
\end{abstract}

Keywords:Dairy farming, milk production, allocative efficiency, cost frontier, sustainable

\section{Introduction}

The food security in India is an evergreen topic due to the deficit amount of food to feed a million stomachs. Natural resources are needed to address the food security measures in any country; agriculture is one of the best options for this. In the agricultural wing, dairy farming address food security issues and at the same time, provides employment opportunities. India is holding the number one position in global milk production. Dairying is considered as an essential subsidiary occupation in India. There are millions of people still depend on dairying for their livelihood. Apart from milk sales, the farmers get additional income by way of sale through cow dung and cow urine. Sustainable dairy farming can be defined as a process of involving in farming activity for a more extended period. The farmers will get to involve in a longer period only if the farming activity is sustainable. To be sustainable, the cost of production has to be feasible for farmers. Sustainability can be measured by analyzing the cost efficiency of dairy farmers. Only if it is allocative efficient (cost-efficient), the dairy farmers will get involved in this activity. The study gives an insight into the cost efficiency of dairy farmers. The Indian dairy sector has shown an exponential growth during past few decades, and the milk production has gone up immensely since independence, resulting this has led India to reach the 
topmost position in the milk production [1].India continues to be the largest producer of milk in the world; with an annual output of 187.749 million tons during the year 2018-2019.

Kerala is a state which is located in the southernmost tip of India with a rich culture of agriculture, and it is the 12th largest dairy market in India. The milk production in Kerala is not showing steady growth; the growth is prolonged.



Fig.1 Trend in Milk Production in India and Kerala

Figure 1 depicts the annual milk production in India and Kerala. The growth in milk production is not linear. The reason is due to the efficiency issue. An inefficient firm is the one which is not able to produce maximum output from its given inputs. [2] The cost of milk production is increasing in Kerala; it is a critical factor for the efficiency of milk production[3]. The profit can be increased either through maximization of the output or minimization of inputs. The dairy farming can be sustainable only if the cost of production can be reduced and where precisely the farmers are excessively using the input. Many documents are stating the dairy farming has no future sustainability due to the high cost of production and young people are not getting attracted to this sector. To analyze the sustainability of dairy farming, it is highly essential to find allocative efficiency concerning milk production. The literature about the allocative efficiency of milk production has not yet observed by any researcher. This has enabled the researcher to estimate the allocative efficiency. The allocative efficiency means the ability of the farm to maximize the profits, by equating the marginal revenue product with the marginal cost of inputs[4]. Only if dairy farming is allocatively efficient, more people will come in and make it sustainable. The study mainly focuses on the allocative efficiency of milk production about three districts in Kerala. The allocative efficiency is analyzed using the stochastic cost frontier method introduced by [5] and [6].

\section{LITERATURE REVIEW}

In Kerala, dairy farming is done by smallholder farmers. Minimal resources characterize them in terms of land, capital, low income, low food security and family-owned labour for doing the farm household works. Similar works are stating this by [7] and [8]. There are literature available on allocative efficiency by [9], [10], [11] and [12]. The articles related to the 
sustainability of the dairy farming express that cost of input variables have a diverse effect on the sustainability of farmers by[13] and [14]. However, there is no information about the allocative efficiency of milk production, which leads to sustainability concerning Kerala scenario. With this background case, this paper tries to explore the allocative efficiency of milk production concerning the Kerala scenario.

\section{METHODOLOGY AND DATA ANALYSIS}

\section{SAMPLING}

The study used a descriptive and qualitative research design to estimate the allocative efficiency. The study was undertaken in Kerala. The Kerala state was divided into three zones viz South zone, Central zone and North zone based on the classification given by the Government of Kerala. From these three zones, three districts viz Thiruvanthapuram, Ernakulam and Malappuram districts were chosen as the sample districts for representing each zones. From each district, 50 dairy farmers were selected using the random sampling method.

\section{DATA COLLECTION}

A total of 150 sample respondents were selected to represent the Kerala dairy farmers using a cross-sectional survey. The period of data collection was from January 2020 to March 2020. A one to one interview method was conducted for analyzing the details about the efficiency. The data was collected from each sample farmers using a face to face interview method. The data mainly include the details about the cost of production and the value of price they receive for per litre of milk. The endogenous variable used in the study is the value of milk production and the exogenous variables used in the study was the cost of green fodder and dry fodder, cost of concentrates and other minerals, labour cost and the veterinary cost. All the cost and the value received on per day for per milch has been recorded in the study.

\section{DATA ANALYSIS}

he data collected through the interview method is analyzed using Cobb-Douglas regression analysis in the form of the cost function to estimate the allocative efficiency. The stochastic frontier cost function is derived from the stochastic production function, and it is a function of output level within the group and of input prices taken [15].The stochastic frontier function was developed by [5] [6]. This estimation made it possible to find out whether the deviation in the allocative efficiency is due to farm-specific factors or random errors. There are a number of studies conducted in the field of stochastic cost functions like [16][17].

The stochastic model can be represented as

$Y_{i}=f\left(X_{i}, \beta\right) \exp \left(V_{i-} U_{i}\right)$

Where,

$Y_{i}=$ Production of $i^{\text {th }}$ farm

$\mathrm{f}(\mathrm{Xi}, \beta)=\mathrm{a}$ function of $\mathrm{X}_{\mathrm{i}}$, of the inputs for the $\mathrm{i}^{\text {th }}$ farm and $\beta$ is the vector of unknown parameters

$\mathrm{V}_{\mathrm{i}}=$ symmetric component of the error term

$\mathrm{U}_{\mathrm{i}}=$ random error

The stochastic cost function model used in the study is 
$Y_{i}=\beta_{0}+\beta_{1} \log X_{1}+\beta_{2} \log X_{2}+\beta_{3} \log X_{3}+\beta_{4} \log X_{4}+\beta_{5} \log X_{5}+V_{i}-U_{i}$

$Y_{i}=$ Total value of milk production in the farm

$\mathrm{X}_{1}=$ Cost of green fodder in Indian Rupee

$\mathrm{X}_{2}=$ Cost of dry fodder in Indian Rupee

$\mathrm{X}_{3}=$ Cost of concentrates and other minerals in Indian Rupee

$\mathrm{X}_{4}=$ Cost of Labour in the farm in Indian Rupee

$\mathrm{X}_{5}=$ Veterinary cost in Indian Rupee

$\beta_{0}=$ Constant Return

$\beta_{1}, \beta_{2}, \beta_{3}, \beta_{4}, \beta_{5}=$ Parameters to be estimated

$\mathrm{V}_{\mathrm{i}}=\mathrm{A}$ random error

$\mathrm{U}_{\mathrm{i}}=$ Half-normal error term

\section{RESEARCH RESULT AND DISCUSSION}

The sustainability of a sector can be identified only if the sector is allocatively efficient. The measurement of allocative efficiency is done through stochastic cost frontier analysis. Table 1 shows the result from the analysis.

Table 1 Stochastic Cost Frontier Function Analysis of Milk Production

\begin{tabular}{cccc}
\hline Variables & Thiruvanthapuram & Ernakulam & Malappuram \\
\hline Green Fodder & $0.4952^{*}$ & 0.1542 & $0.3037^{*}$ \\
Dry Fodder & $-.3801^{*}$ & 0.2810 & 0.1142 \\
Concentrates and other & $0.20917^{*}$ & $0.62974^{*}$ & $0.3072^{*}$ \\
Minerals & & & \\
Labor Charges & $-0.8565^{*}$ & $0.4328^{*}$ & $-0.3187^{*}$ \\
Veterinary Cost & -0.76424 & $0.26142^{*}$ & 0.1243 \\
Constant & 0.4952 & 0.39710 & 0.4793 \\
The variance ratio & 0.7136 & .92218 & 0.99 \\
Mean Allocative Efficiency & 66.56 & 61.3 & 63.4 \\
\hline
\end{tabular}

* Significant at five percent level, the value mentioned in the table is the coefficient values of the corresponding variables. The significant is found using $t$ values of each variables.

Table 1 results reveal that the mean allocative efficiency is 66.56 per cent in Thiruvanthapuram district, 61.3 per cent in Ernakulam district and 63.4 per cent in Malappuram district. All three districts are performing on the same range of allocative efficiency. The reason for the normal rage of the efficiency is because of the high cost of production involved in the sector and the dependence on the external resources for the production.

The cost of concentrates and other minerals are positively and significantly ( $\mathrm{p}$-value is less than 0.05 ) influencing the value of milk production. This implies that any one per cent increase in the cost of concentrates and other minerals will increase the value of milk production by the 20.917 per cent in Thiruvanthapuram district, 62.97 per cent in Ernakulam district and 30.72 per cent in Malappuram district. The cost of green fodder is positive and insignificantly influencing in Ernakulam district, and it is significantly influencing in Thiruvanthapuram district and Malappuram district. The cost of dry fodder is negatively and significantly 
influencing the value of milk production in Thiruvanthapuram district, which implies that any one per cent increase in the cost of dry fodder will decrease the value of milk production by 38.01 per cent. In the other districts, the cost of dry fodder is positive and insignificantly influences the value of milk production. The labor charges are significantly influencing in all three districts but a positive influence in Ernakulam district and negatively influencing in Thiruvanthapuram district and Malappuram district. The cost of veterinary is positively influencing the value of milk production in Ernakulam district alone. From the table, it is well understood that cost of labor, and the veterinary cost is the significant cost affecting the dairy farmer's cost of production. The labor cost in Kerala is very high; the only way to reduce is to make use of family labor as much as possible. The veterinary cost can be reduced by giving the farmers the services at a subsidized rate or free of cost.

The dairy farm-specific allocative efficiency is estimated based on the allocative efficiency scores. The range of scores is being adopted [1]. The dairy farmers with the efficiency scores above 90 per cent are treated as the most efficient group, medium efficient group (between 80 and 90 per cent ), moderate efficient group ( between 70 and 80 per cent ) and the least efficient group ( below 70 per cent ).

Table 2 Farm Specific Allocative Efficiency Scores

\begin{tabular}{ccccc}
\hline \multirow{2}{*}{$\begin{array}{c}\text { Ellocative } \\
\text { Efficiency }\end{array}$} & \multicolumn{4}{c}{ Number of Farmers } \\
\cline { 2 - 5 } Thiruvanthapuram & Ernakulam & Malappuram & Total \\
\hline Below 70 & 31 & 28 & 28 & 87 \\
Above 70 and & $(35.63)$ & $(32.18)$ & $(32.18)$ & $(58)$ \\
Below 80 & 11 & 10 & 7 & 28 \\
Above 80 and & $(39.28)$ & $(35.71)$ & $(25)$ & $(18.66)$ \\
Below 90 & 8 & 9 & 6 & 23 \\
Above 90 & $(34.78)$ & $(39.13)$ & $(26.08)$ & $(15.33)$ \\
& 0 & 2 & 8 & 10 \\
Total & & $(20)$ & $(80)$ & $(6.66)$ \\
& $(33.33)$ & 50 & 50 & 150 \\
& $(33.33)$ & $(33.33)$ & $(100)$ \\
\hline (Figures in parentheses indicate percentage), the number of farmers is given in the table
\end{tabular}

(Figures in parentheses indicate percentage), the number of farmers is given in the table

Table 2 reveals that 58 percentages of farmers are in below 70 per cent of allocative efficiency. The farmers from Thiruvananthapuram district have lowest allocative efficiency below 70 per cent, due to the conventional method of farming. The labor usage is over-utilized in their farms. Only 6.66 per cent of farmers are performing high in the allocative efficiency (Above 90 per cent).

The sustainability of dairy farming has a direct link with allocative efficiency. Only if the farmers can maximize the output from the minimum optimization of inputs at their market price, they will be able to scale up their activities. In this case, the dairy farmers are not able to scale up their activities since the cost of production is very high. Currently, the farmers are performing on a 60 per cent level of allocative efficiency. Only if they are allocatively efficient, the farmers can economically produce more output from milk production. 


\section{SUMMARY}

The study on the estimation of milk production reveals that the average mean efficiency of all the districts is 63.75 per cent, and there is still room for improvement by 36.25 per cent. The estimation showed that variations occurred in the allocative efficiency is under the control of farmers. Thiruvanthapuram district has 71 per cent of the variation in the allocative efficiency, Ernakulam district has 92 per cent, and Malappuram district has 99 per cent variation, all these variations are under the control of farmers. This implies that there is a lot more efficient usage of inputs needed to produce the maximum current output. Only if the farmers attain an excellent high level of allocative efficiency, the farmers will be able to earn a good return and increase their savings. This will make the sector sustainable. According to the current efficiency level, the sustainability of the dairy sector in Kerala is a big question. There should be a policy revision to make the dairy sector a cost-effective sector. The policy revisions should be in the form of subsidized feed inputs; it should be made available to farmers every month. The value of milk also needs to be revised accordingly with the cost of production. This will enable the farmers to continue in this sector and make it sustainable.

\section{IMPLICATIONS / LIMITATIONS AND SUGGESTIONS FOR FURTHER RESEARCH}

The study focuses on the allocative efficiency mainly, because only if the farmers are allocatively efficient, they will be interested in staying in this activity for a more extended period and making this sector sustainable option for the farmers. The sustainability purely depends on the cost factor, if the farm option is not profitable for them, then the farmers will not continue, and the dairy farming will be less sustainable for them. Like any other research, this paper also points out certain limitations. The studies related to allocative efficiency of milk production in Kerala was not available; this made the researcher challenging to compare with the previous literature or data on this. The study was limited to a few samples, so a generalization on this cannot be made to enhance more generality in this; a detailed study on the allocative efficiency is needed for further policy changes. A cross-state comparison can be made to analyses which state is performing better with the allocative efficiency.

\section{References}

[1] A. S. S. Pandian, K. N. Selvakumar, M. Prabu, and B. Ganeshkumar, "TECHNICAL EFFICIENCY OF MILK PRODUCTION IN TAMIL NADU of India : FRONTIER PRODUCTION FUNCTION APPROACH," Asian J. Dairy Food Res., vol. 31, no. 4, pp. 264-267, 2015.

[2] A. Al-sharafat, "Technical Efficiency of Dairy Farms : A Stochastic Frontier Application on Dairy Farms in Jordan," vol. 5, no. 3, 2013, doi: 10.5539/jas.v5n3p45.

[3] M. Umamageswari, P. K. Dixit, and M. Sivaram, "Economics of milk production in Tamil Nadu - A comparative study,” vol. 70, no. September 2016, pp. 221-227, 2017.

[4] A. Econometrics, "On Measuring Economic Efficiency Author ( s): K . P . Kalirajan Published by : Wiley Stable URL : http://www.jstor.org/stable/2096556," vol. 5, no. 1, pp. 75-85, 2016. 
[5] D. Aigner, C. A. K. Lovell, and P. Schmidt, "PI *," vol. 6, pp. 21-37, 1977.

[6] "Efficiency Estimation from Cobb-Douglas Production Functions with Composed Error Author ( s ): Wim Meeusen and Julien van Den Broeck Source : International Economic Review, Vol . 18 , No . 2 ( Jun ., 1977 ), pp . 435-444 Published by : Wiley for the Econ," vol. 18, no. 2, pp. 435-444, 2018.

[7] K. N. Nair, "Technological change in milk production - a review of some critical issues with reference to South Asia.," Econ. Polit. Wkly., vol. 17, no. 13, 1982.

[8] S. George, "Stemming Operation Flood Towards an Alternative Dairy Policy for India," Econ. Polit. Wkly., vol. 22, no. 39, pp. 1654-1663, 1987, [Online]. Available: http://www.jstor.org/stable/4377549.

[9] M. Gautam, H. K. Nagarajan, and K. C. Pradhan, "Technical, economic and allocative efficiency and its determinants of Indian agricultural farmers using ARIS/ REDS panel data," NCAER Work. Pap. Decent. Rural Gov. India, no. 16, 2012.

[10] S. Chiona, "Technical and Allocative Efficiency of Smallholder Maize Farmers in Zambia," J. Econ. Sustain. Dev., vol. 5, no. 15, pp. 1-64, 2011.

[11] M. Sajjad and M. Khan, "Economic Efficiency of Milk Production in District Peshawer : a Stochastic Frontier Approach," J. Agric, vol. 26, no. 4, pp. 655-663, 2010.

[12] JAFES, “International Scientific Journal,” Int. Sci. J., vol. 67, no. 477, 2016.

[13] S. S. Kumar, S. Rajvir, U. K. Mishra, and D. J. Mishra, "Strategies for Sustainable Dairy Farming in India : A Review,” vol. 2, pp. 42-44, 2012.

[14] H. Nazir, "Sustainability Assessment of Dairy Production Systems in Uttarakhand Hills of India,” Int. J. Pure Appl. Biosci., vol. 5, no. 2, pp. 215-229, 2017, doi: 10.18782/2320-7051.2778.

[15] W. D. Bradford, A. N. Kleit, M. A. Krousel-wood, and N. Richard, "Stochastic Frontier Estimation of Cost Models within the Hospital Author ( s ): W . David Bradford, Andrew N . Kleit, Marie A . Krousel-Wood and Richard N . Re Source : The Review of Economics and Statistics , Vol . 83 , No . 2 ( May , 2001 ), pp . 302-," vol. 83, no. 2, pp. 302-309, 2016.

[16] J. Puig-Junoy and V. Ortun, "Cost Efficiency in Primary Care Contracting: A Stochastic Frontier Cost Function Approach," SSRN Electron. J., no. July, 2011, doi: $10.2139 /$ ssrn.563242.

[17] J. Antonio and R. Aso, "Estimation of stochastic frontier cost function model : An empirical analysis of industrial pollution in Spain." 